\title{
Does Masticatory Ability Contribute to Nutritional Status in Older Individuals?
}

\author{
Keiko Fujimoto ${ }^{1}$, Hideki Suito ${ }^{2}$, Kan Nagao ${ }^{1}$ and Tetsuo Ichikawa ${ }^{1, *(D)}$ \\ 1 Department of Prosthodontics and Oral Rehabilitation, Graduate School of Biomedical Sciences, \\ Tokushima University, Tokushima 770-8504, Japan; fujimoto.keiko@tokushima-u.ac.jp (K.F.); \\ kan@tokushima-u.ac.jp (K.N.) \\ 2 Department of Oral and Maxillofacial Radiology, Graduate School of Dentistry, Kyushu University, \\ Fukuoka 812-8582, Japan; h-suito@rad.dent.kyushu-u.ac.jp \\ * Correspondence: ichi@tokushima-u.ac.jp
}

Received: 17 August 2020; Accepted: 24 September 2020; Published: 9 October 2020

\begin{abstract}
Mastication plays a primary role in the process of eating. Hence, compromised masticatory ability may affect the nutrition and quality of life, which are particularly important concerns among older individuals. It remains unclear how is the masticatory ability assessed regarding the nutritional status. We examined the effect of various oral factors on three masticatory ability tests conducted among older individuals. A total of 100 older individuals were enrolled in this study. Body mass index (BMI) as an indicator of nutritional status; and age, sex, and the number of occlusal and molar occlusal supports as clinical attributes were recorded. Three masticatory ability tests (masticatory efficiency, masticatory score, and satisfaction with mastication) were conducted, and tongue pressure, cheek pressure, and occlusal force were assessed as oral functions. A significant but weak correlation was found between masticatory efficiency and the masticatory score, but not between masticatory efficiency and satisfaction score. Objective masticatory efficiency was strongly associated with objective oral factors, whereas subjective assessments of masticatory ability (masticatory score and satisfaction score) were not. Furthermore, BMI was significantly associated with subjective assessments of masticatory ability but not with objective masticatory efficiency. Both subjective and objective assessments of masticatory ability, along with considerations of nutritional formulations, are required for the maintenance and improvement of nutritional status in older individuals.
\end{abstract}

Keywords: nutritional status; body mass index; mastication; oral factor; masticatory efficiency; older individuals

\section{Introduction}

Individuals who are overweight and obese are at an increased risk for many diseases and health conditions, and there is a direct relationship between high body mass index (BMI) and all-cause mortality [1-3]. Conversely, undernutrition, as indicated by a low BMI, is also associated with an increased risk of all-cause mortality; this is of particular concern among frail older adults [4,5]. Undernutrition has a varied etiology, of which impaired masticatory ability is the primary focus in the field of dentistry. Impaired masticatory ability may cause difficulties in eating, which in turn can affect the quality of life, increase the risk of undernutrition, and lead to the need for nursing care [6-8].

It remains unclear how masticatory ability affects the nutritional status. The relationship of subjective satisfaction with masticatory ability and objective masticatory ability (assessed via masticatory efficiency tests) in older individuals is inconclusive, with previous studies showing either a significant positive correlation [9] or the lack of a correlation [10]. In our own clinical observations, we have found that patients may be subjectively satisfied with their masticatory ability despite having 
a low masticatory efficiency; conversely, other patients may be dissatisfied despite having a high masticatory efficiency. While subjective self-assessments are not always in agreement with objective measurements [11,12], it is essential to elucidate the extent to which either assessment may be used for nutrition-related guidance in older individuals.

While it is well-known that mastication plays a primary role in the process of eating and that oral factors affect the masticatory ability in healthy adults, the effects in older individuals remain unclear. Some studies have suggested that masticatory ability affected by occlusal force and other occlusal factors $[13,14]$ and also by other oral factors such as the strength and functional capacity of the tongue, lip, and cheek muscles $[15,16]$. However, the relationships between these factors and subjective assessments of masticatory ability have hitherto not been investigated with respect to nutritional status.

Hence, the purpose of this study was to compare the effects of various oral factors on three masticatory ability tests conducted among older individuals, with the overarching aim of determining the objective and subjective components required to guide the maintenance and improvement of nutritional status in older adults. The hypothesis was that low masticatory ability results in low nutritional status in older individuals.

\section{Materials and Methods}

\subsection{Participants}

Consecutive elderly patients reporting for regular maintenance treatment were recruited over a five-month period from the outpatient clinic of the oral rehabilitation division at Tokushima University Hospital (Tokushima, Japan).

The inclusion criteria comprised the following: (1) age over 65 years and (2) absence of a prior history of cerebrovascular disease, neurodegenerative disease, dementia, malignant tumors, and other diseases that can cause eating difficulties or dysphagia. The study was conducted in accordance with the Declaration of Helsinki and was approved by the Ethics Committee of the Tokushima University Hospital (approval number: 2225). All participants signed a written informed consent form prior to study participation.

\subsection{Nutrition Status}

Body height and weight were self-reported in participant interviews and were subsequently used to calculate the BMI for assessing the nutritional status.

\subsection{Basic Clinical Assessments}

All measurements were carried out by the same examiner (K.F.) to eliminate inter-rater variability. Prior to the commencement of the study, the examiner was trained and calibrated in performing the clinical measurements.

The age, sex, number of occlusal supports (OSN), and number of molar occlusal supports (MOSN) were recorded. The OSN and MOSN were documented during an oral examination. The OSN were obtained by counting the number of occluding tooth pairs (values ranging from 0 to 14). The MOSN were determined by counting the number of occluding molar pairs (values ranging from 0 to 8 ).

\subsection{Assessments of Masticatory Ability}

Subjective masticatory ability was assessed using two scales: (1) a masticatory score and (2) a conventional visual analog scale (VAS) score that evaluated satisfaction with mastication. The masticatory score was assessed using a questionnaire, which classified 25 food items into five categories based on ease of mastication for these items. Participants were asked to rate their ability to eat each food item, and the masticatory score was calculated as shown in Table $1[17,18]$. 
Table 1. The 25 food items and formula for calculating the masticatory score.

\begin{tabular}{|c|c|c|c|c|c|}
\hline Food Group & I & II & III & IV & V \\
\hline Foods & $\begin{array}{l}\square \text { Bananas } \\
\square \text { Boiled } \\
\text { cabbage } \\
\square \text { Boiled carrots } \\
\square \text { Boiled taro } \\
\square \text { Boiled onions }\end{array}$ & $\begin{array}{l}\square \text { Strawberries } \\
\square \text { Ham } \\
\square \text { Boiled fish } \\
\text { paste } \\
\square \text { Konnyaku } \\
\square \text { Boiled kombu }\end{array}$ & $\begin{array}{l}\square \text { Fried chicken } \\
\square \text { Roast chicken } \\
\square \text { Apples } \\
\square \text { Pickled } \\
\text { eggplants } \\
\square \text { Raw cabbage }\end{array}$ & $\begin{array}{l}\square \text { Roast pork } \\
\square \text { Pickled } \\
\text { radishes } \\
\square \text { Rice cakes } \\
\square \text { Peanuts } \\
\square \text { Slice draw } \\
\text { cuttlefish }\end{array}$ & $\begin{array}{l}\square \text { Raw carrots } \\
\square \text { Takuwan } \\
\square \text { Vinegared } \\
\text { octopus } \\
\square \text { Raw abalone } \\
\square \text { Dried } \\
\text { cuttlefish }\end{array}$ \\
\hline
\end{tabular}

$\square$ Assessment point: [2] easily eaten, [1] eaten in difficulty, [0] cannot be eaten. A-E indicate the mean score of the assessment points in the five groups (I-V). Masticatory score $=[A+1.06 * B+1.22 * C+1.39 * D+2.23 * E] / 13.8 \times 100$.

The VAS score for satisfaction with mastication consisted of a straight horizontal line, $100 \mathrm{~mm}$ in length, beginning with "cannot chew at all" $(0 \mathrm{~mm})$ and ending with "can chew very well" (100 mm). Participants marked on the line with an " $X$ " after being asked the following question: "Can you chew well?"

Objective masticatory efficiency was assessed using a masticatory ability testing system (Gluco Sensor GS-II, GC Co., Tokyo, Japan) [19]. Participants were asked to chew $2 \mathrm{~g}$ of gummy jelly for $20 \mathrm{~s}$ on their habitual chewing side and then to gently expectorate it with $10 \mathrm{~mL}$ of water. The glucose level in the eluted filtrate is reflective of the masticatory efficiency and the glucose concentration was measured using the device mentioned above (Figure 1).
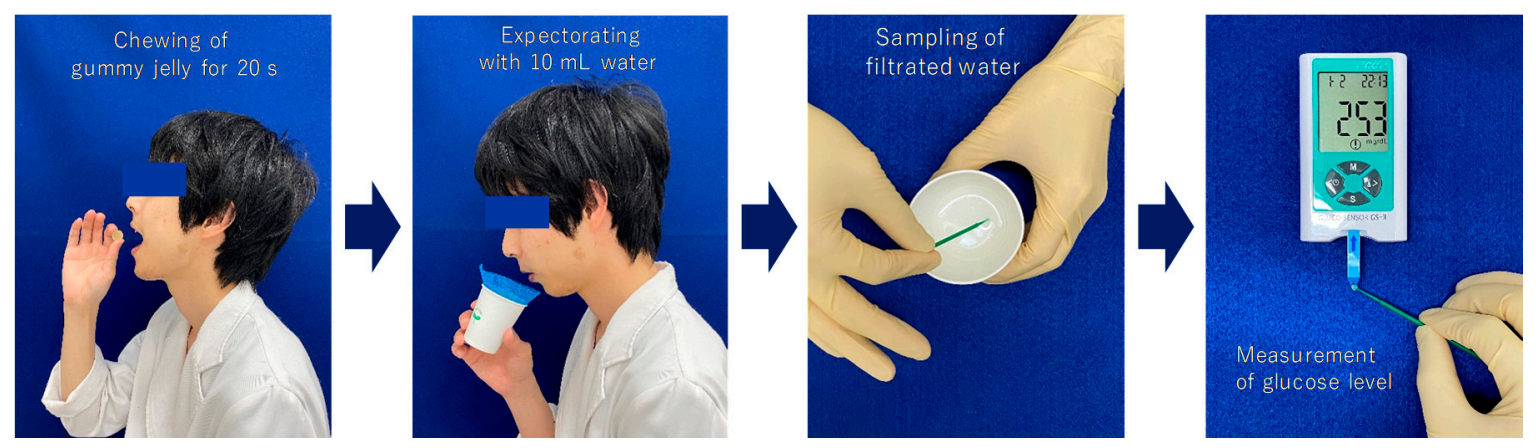

Figure 1. Protocol for the masticatory efficiency test.

\subsection{Assessments of Oral Muscle Strength: Tongue Pressure, Cheek Pressure, and Occlusal Force}

A device previously designed to measure tongue pressure (JMS Tongue Pressure Measuring Instrument, JMS Co., Hiroshima, Japan) was used to determine both tongue and cheek pressures (Figure 2) [20]. For the determination of tongue pressure, a disposable balloon probe was inserted into the participant's mouth, and the participant was instructed to hold the probe gently with the front teeth. The participants were instructed to press their tongue against the pressure-sensing portion of the probe with maximum force for $7 \mathrm{~s}$. For the determination of cheek pressure, the balloon probe was inserted between the right buccal mucosa and buccal surfaces of the upper and lower first molars, with the teeth in occlusion. Patients were instructed to purse their lips and press their cheek against the pressure-sensing portion of the probe with maximum force for $7 \mathrm{~s}$. Both tongue and cheek pressures were measured three times, and the mean value was taken as the representative value. 

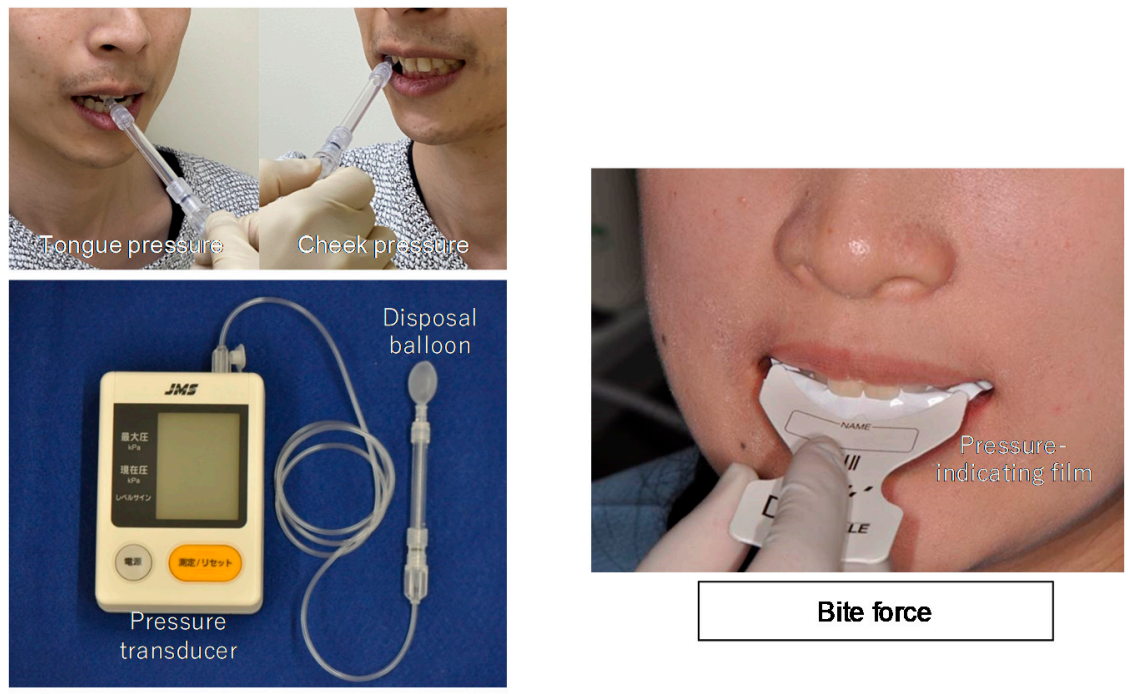

Tongue and cheek pressure

Figure 2. Description of tongue pressure, cheek pressure, and bite force measurements.

Occlusal force was measured using a pressure-indicating film (Dental Prescale 50H, GC Co., Tokyo, Japan) and analyzed using an Occluser 709 (GC Co., Tokyo, Japan) (Figure 2) [21]. The film was placed between the maxillary and mandibular teeth, and the participants were instructed to bite with the maximum force for $3 \mathrm{~s}$. The occlusal force was measured three times, and the maximum value was taken as the representative value.

\subsection{Statistical Analyses}

All hypotheses were specified prior to data collection. Before the pre-specified analyses were conducted, the participants were categorized into the following two groups based on the median of each masticatory ability test (masticatory efficiency, masticatory score, and VAS satisfaction score): the upper-category group (UG) and lower-category group (LG). Each reciprocal relationship between the three types of masticatory ability tests was examined using the Spearman's correlation coefficient test. The differences in each masticatory ability test between the UG and LG were analyzed using the chi-squared test and Mann-Whitney U test.

A univariate logistic regression (ULR) analysis was performed using the forced-entry method to determine the association between the masticatory ability test score (dependent variable) and potential explanatory variables. A multivariate logistic regression (MLR) analysis was performed to identify interactions between variables, and to consider these for further analysis. Variables were selected using the step-down procedure and likelihood ratio test.

Prior to the above tests, the Shapiro-Wilk test was used to determine whether the data followed a normal distribution. The interclass correlation coefficient was also calculated to determine the reliability of the measurements. The significance level for all tests was set at $p=0.05$. SPSS ver. 24.0 for Mac (IBM Co., Tokyo, Japan) was used for all statistical analyses.

\section{Results}

One hundred participants (53 males and 47 females; mean age, $75.3 \pm 6.5$ years) were enrolled in this study. The means and standard deviations (SDs) for masticatory efficiency, masticatory score, and VAS satisfaction score were $137.7 \pm 57.6,89.1 \pm 15.7$, and $76.0 \pm 19.5$, respectively. The median values for the categorizations of the UG and LG from the regression analysis are shown in Table 2. 
Table 2. Regression analysis categorizations for the three masticatory ability assessments.

\begin{tabular}{cccc}
\hline Groups & $\begin{array}{c}\text { Masticatory Efficiency } \\
\text { Test }[\mathrm{mg} / \mathrm{dL}]\end{array}$ & $\begin{array}{c}\text { Masticatory } \\
\text { Score }\end{array}$ & $\begin{array}{c}\text { Satisfaction with Mastication } \\
\text { (VAS Score) }\end{array}$ \\
\hline $\begin{array}{c}\text { Upper-category group } \\
\text { (UG) }\end{array}$ & $\geq 126.0$ & $\geq 96.7$ & $\geq 77.0$ \\
$\begin{array}{c}\text { Lower-category group } \\
\text { (LG) }\end{array}$ & $<126.0$ & $<96.7$ & $<77.0$ \\
Mean and SD & $137.7 \pm 57.6$ & $89.1 \pm 15.7$ & $76.0 \pm 19.5$ \\
\hline
\end{tabular}

Figure 3 shows the relationships between each test pair among the three masticatory ability tests. Significant but weak correlations were observed between masticatory efficiency and masticatory score $(p=0.380)$, and between masticatory score and VAS satisfaction score $(p=0.337)$. No significant correlation $(p=0.184)$ was observed between masticatory efficiency and VAS satisfaction score.
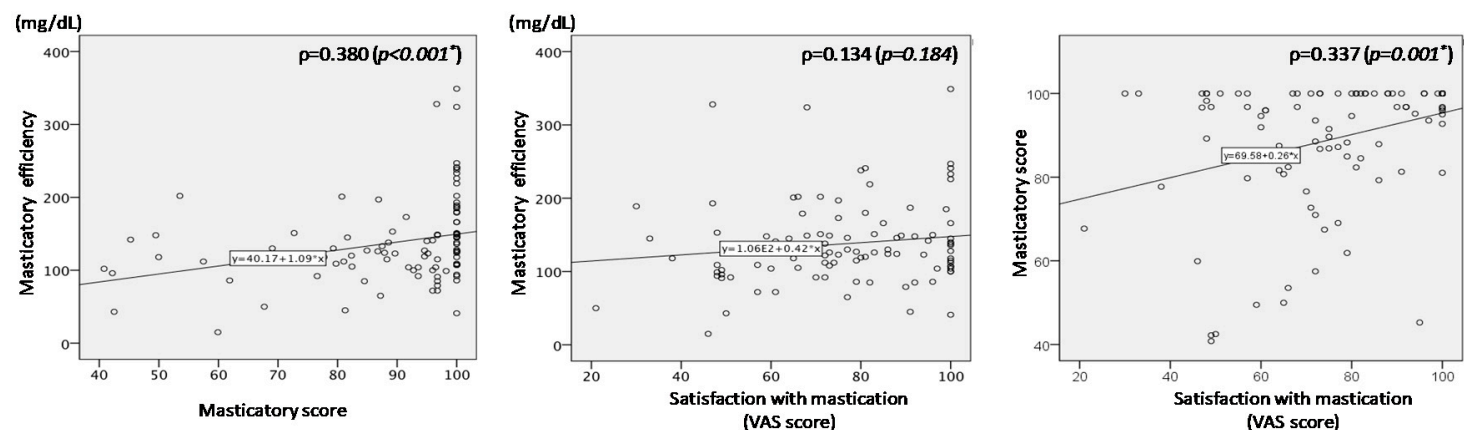

Figure 3. Reciprocal relationships between the three masticatory ability tests. ${ }^{*} p<0.05$.

Table 3 shows the means and SDs of measurement factors in the two groups for each masticatory ability test. The distributions of sex and age were not different between the two groups. Overall, measurement values in the UG were better than those in the LG; cheek pressure was an exception.

Table 4 shows the results of the logistic regression analysis. All correlation coefficients between each parameter were less than 0.9 , and the interclass correlation coefficients for all parameters were greater than 0.8. Acceptable reproducibility of the measurements was confirmed.

The associations of masticatory efficiency with the OSN, MOSN, tongue pressure, and occlusal force were determined via ULR analysis. The MOSN and tongue pressure were found to be independent predictors of masticatory efficiency in the final MLR model. The goodness of fit of the regression model was determined using the Hosmer-Lemeshow test $(p=0.545)$, and the percentage of correct classifications was $70 \%$.

The associations of masticatory score with the OSN, MOSN, BMI, and occlusal force were determined via ULR analysis. The OSN, cheek pressure, and BMI were found to be independent predictors of masticatory score in the final MLR model. The goodness of fit of the regression model was determined using the Hosmer-Lemeshow test $(p=0.698)$, and the percentage of correct classifications was $71 \%$.

The associations of VAS satisfaction score with the OSN, MOSN, and BMI were determined via ULR analysis. Both age and BMI were found to be independent predictors of VAS satisfaction score in the final MLR model. The goodness of fit of the regression model was determined using the Hosmer-Lemeshow test $(p=0.606)$, and the percentage of correct classifications was $68 \%$. 
Table 3. Differences in measurement factors between the upper and lower category groups in assessments of masticatory ability.

\begin{tabular}{|c|c|c|c|c|c|c|c|c|c|c|}
\hline \multirow[b]{2}{*}{ Measurement Factors } & \multirow{2}{*}{$\begin{array}{c}\text { Total } \\
n=100\end{array}$} & \multicolumn{3}{|c|}{ Masticatory Efficiency } & \multicolumn{2}{|c|}{ Masticatory Score } & \multicolumn{4}{|c|}{ Satisfaction with Mastication (VAS Score) } \\
\hline & & $\begin{array}{c}\text { LG } \\
n=51\end{array}$ & $\begin{array}{c}\text { UG } \\
n=49\end{array}$ & $p$-Value & $\begin{array}{c}\text { LG } \\
n=50\end{array}$ & $\begin{array}{c}\text { UG } \\
n=50\end{array}$ & $p$-Value & $\begin{array}{c}\text { LG } \\
n=51\end{array}$ & $\begin{array}{c}\text { UG } \\
n=49\end{array}$ & $p$-Value \\
\hline $\begin{array}{l}\text { Nutritional status: BMI } \\
\qquad\left(\mathrm{kg} / \mathrm{m}^{2}\right)\end{array}$ & $22.6 \pm 3.3$ & $22.5 \pm 3.0$ & $22.7 \pm 3.5$ & 0.634 & $21.8 \pm 2.7$ & $23.3 \pm 3.6$ & $0.013^{*}$ & $21.6 \pm 2.9$ & $23.6 \pm 3.3$ & $0.001 *$ \\
\hline \multicolumn{11}{|c|}{ Basic attributes } \\
\hline Sex (male:female) & $53: 47$ & 29:22 & $24: 25$ & $0.430^{\mathrm{a}}$ & $25: 25$ & 28:22 & $0.548^{a}$ & $26: 25$ & $27: 22$ & $0.680^{\mathrm{a}}$ \\
\hline Age & $75.3 \pm 6.5$ & $75.9 \pm 6.7$ & $74.6 \pm 6.2$ & 0.335 & $76.4 \pm 6.5$ & $74.2 \pm 6.2$ & 0.111 & $76.5 \pm 6.5$ & $74.0 \pm 6.3$ & 0.064 \\
\hline \multicolumn{11}{|c|}{ Occlusal supports } \\
\hline Occlusal supports (unit) & $4.1 \pm 5.0$ & $2.4 \pm 3.5$ & $5.9 \pm 5.7$ & $0.003 *$ & $2.3 \pm 3.9$ & $5.9 \pm 5.4$ & $0.000 *$ & $3.0 \pm 4.2$ & $5.3 \pm 5.5$ & 0.059 \\
\hline $\begin{array}{l}\text { Molar occlusal supports } \\
\text { (unit) }\end{array}$ & $1.7 \pm 2.7$ & $0.63 \pm 1.6$ & $2.7 \pm 3.2$ & 0.001 * & $0.8 \pm 1.9$ & $2.5 \pm 3.1$ & 0.003 * & $1.0 \pm 2.2$ & $2.3 \pm 3.1$ & $0.027 *$ \\
\hline \multicolumn{11}{|c|}{ Gnathological muscle strength } \\
\hline Tongue pressure $(\mathrm{kPa})$ & $27.8 \pm 8.4$ & $25.7 \pm 8.3$ & $30.0 \pm 8.1$ & $0.017^{*}$ & $27.2 \pm 7.4$ & $28.4 \pm 9.4$ & 0.282 & $27.0 \pm 8.9$ & $28.6 \pm 7.8$ & 0.370 \\
\hline Cheek pressure $(\mathrm{kPa})$ & $16.4 \pm 4.0$ & $16.0 \pm 4.4$ & $16.9 \pm 3.4$ & 0.202 & $17.2 \pm 3.6$ & $15.7 \pm 4.2$ & 0.110 & $16.4 \pm 4.4$ & $16.5 \pm 3.4$ & 0.983 \\
\hline Occlusal force (N) & $274.7 \pm 212.4$ & $215.1 \pm 183.0$ & $336.9 \pm 224.6$ & $0.000 *$ & $229.7 \pm 204.9$ & $319.8 \pm 212.1$ & $0.003 *$ & $266.8 \pm 209.8$ & $283.0 \pm 217.0$ & 0.617 \\
\hline
\end{tabular}


Table 4. Regression analysis of the association between oral factors and masticatory ability test.

\begin{tabular}{|c|c|c|c|c|c|c|c|c|c|}
\hline \multirow{3}{*}{ Tests } & \multirow{3}{*}{ Measurement Actors } & \multicolumn{4}{|c|}{ Univariate Logistic Regression Analysis (ULR) } & \multicolumn{4}{|c|}{ Multivariate Logistic Regression Analysis (MLR) } \\
\hline & & \multirow{2}{*}{ Odds Ratio } & \multicolumn{2}{|c|}{$95 \% \mathrm{CI}$} & \multirow{2}{*}{$p$-Value } & \multirow{2}{*}{ Odds Ratio } & \multicolumn{2}{|c|}{$95 \% \mathrm{CI}$} & \multirow{2}{*}{$p$-Value } \\
\hline & & & Lower Limit & Upper Limit & & & Lower Limit & Upper Limit & \\
\hline \multirow{11}{*}{ Masticatory efficiency } & Nutritional status: $\mathrm{BMI}\left(\mathrm{kg} / \mathrm{m}^{2}\right)$ & 1.023 & 0.907 & 1.155 & 0.708 & & & & \\
\hline & \multicolumn{9}{|c|}{ Basic attributes } \\
\hline & Sex & 0.967 & 0.909 & 1.029 & 0.288 & & & & \\
\hline & Age & 1.373 & 0.624 & 3.019 & 0.430 & & & & \\
\hline & \multicolumn{9}{|c|}{ Occlusal supports } \\
\hline & Occlusal supports (unit) & 1.169 & 1.066 & 1.282 & $0.001 *$ & & & & \\
\hline & Molar occlusal supports (unit) & 1.430 & 1.167 & 1.753 & $0.001 *$ & 1.464 & 1.178 & 1.820 & 0.001 * \\
\hline & \multicolumn{9}{|c|}{ Oral muscle strength } \\
\hline & Tongue pressure $(\mathrm{kPa})$ & 1.069 & 1.015 & 1.127 & $0.012 *$ & 1.077 & 1.018 & 1.140 & $0.010^{*}$ \\
\hline & Cheek pressure $(\mathrm{kPa})$ & 1.056 & 0.954 & 1.168 & 0.294 & & & & \\
\hline & Occlusal force $(\mathrm{N})$ & 1.003 & 1.001 & 1.006 & $0.007^{*}$ & & & & \\
\hline \multirow{11}{*}{ Masticatory score } & Nutritional status: BMI $\left(\mathrm{kg} / \mathrm{m}^{2}\right)$ & 1.161 & 1.016 & 1.326 & $0.028 *$ & 1.228 & 1.059 & 1.425 & $0.007^{*}$ \\
\hline & \multicolumn{9}{|c|}{ Basic attributes } \\
\hline & Sex & 0.948 & 0.890 & 1.009 & 0.093 & & & & \\
\hline & Age & 0.786 & 0.358 & 1.726 & 0.548 & & & & \\
\hline & \multicolumn{9}{|c|}{ Occlusal supports } \\
\hline & Occlusal supports (unit) & 1.178 & 1.072 & 1.294 & $0.001 *$ & 1.199 & 1.084 & 1.328 & $0.000 *$ \\
\hline & Molar occlusal supports (unit) & 1.300 & 1.089 & 1.553 & $0.004 *$ & & & & \\
\hline & \multicolumn{9}{|c|}{ Oral muscle strength } \\
\hline & Tongue pressure $(\mathrm{kPa})$ & 1.017 & 0.970 & 1.067 & 0.473 & & & & \\
\hline & Cheek pressure (kPa) & 0.908 & 0.818 & 1.009 & 0.072 & 0.854 & 0.757 & 0.964 & 0.011 * \\
\hline & Occlusal force $(\mathrm{N})$ & 1.002 & 1.002 & 1.005 & $0.042 *$ & & & & \\
\hline \multirow{11}{*}{$\begin{array}{c}\text { Satisfaction with } \\
\text { mastication(VAS score) }\end{array}$} & Nutritional status: BMI $\left(\mathrm{kg} / \mathrm{m}^{2}\right)$ & 1.243 & 1.074 & 1.437 & $0.003 *$ & 1.274 & 1.094 & 1.484 & $0.002 *$ \\
\hline & \multicolumn{9}{|c|}{ Basic attributes } \\
\hline & Sex & 0.847 & 0.386 & 1.860 & 0.680 & & & & \\
\hline & Age & 0.942 & 0.884 & 1.003 & 0.064 & 0.925 & 0.863 & 0.991 & $0.027^{*}$ \\
\hline & \multicolumn{9}{|c|}{ Occlusal supports } \\
\hline & Occlusal supports (unit) & 1.099 & 1.011 & 1.195 & $0.027 *$ & & & & \\
\hline & Molar occlusal supports (unit) & 1.203 & 1.025 & 1.411 & $0.023 *$ & & & & \\
\hline & \multicolumn{9}{|c|}{ Oral muscle strength } \\
\hline & Tongue pressure $(\mathrm{kPa})$ & 1.024 & 0.976 & 1.074 & 0.331 & & & & \\
\hline & Cheek pressure (kPa) & 1.010 & 0.914 & 1.115 & 0.848 & & & & \\
\hline & Occlusal force $(\mathrm{N})$ & 1.000 & 0.998 & 1.001 & 0.703 & & & & \\
\hline
\end{tabular}




\section{Discussion}

Undernutrition is a major factor in the deterioration of health status, especially among frail elderly individuals [22-24]. The food intake factors that result in undernutrition can be influenced by the following factors: masticatory ability and eating manner, environment/ability to prepare foods, food preference and literacy [25-28]. While nutritional status will be mainly dependent on food preference and food literacy in younger individuals, masticatory ability and satisfaction with mastication assume a greater importance in older individuals [29]. In this study, we aimed to determine the most appropriate components that should be evaluated in masticatory assessments for older individuals, in order to improve the nutritional status.

In this study, we compared three masticatory ability tests among older individuals; no such comparisons have been made to date. The validity of the objective masticatory efficiency test has been previously demonstrated in studies utilizing the conventional sieve method as a gold standard [19]. The masticatory score is considered a quasi-subjective evaluation, despite being a quantitative form of assessment. This is because food intake standards vary by country; thus, every country uses its own specific food intake questionnaire. In Japan, the masticatory score described has been previously validated using the conventional sieve method [17] and is currently widely used in Japan. The evaluation of satisfaction with mastication using the VAS is a completely subjective assessment. Participants were divided into two groups (UG and LG) according to the median scores obtained in the three masticatory ability tests. The median value was selected as the threshold because the data of masticatory ability tests had distribution biases. Moreover, the meaning of the cut-off values was unclear in the three tests.

In the comparisons among the three masticatory ability tests, significant but weak correlations were found between masticatory efficiency and masticatory score, and between masticatory score and VAS satisfaction score; however, no significant correlation was found between masticatory efficiency and VAS satisfaction score. Thus, the purely subjective assessment (VAS satisfaction) had a poorer correlation to the purely objective assessment (masticatory efficiency), compared with the partially subjective assessment (masticatory score).

The significant explanatory factors were also found to differ for each masticatory ability test. With regard to objective masticatory efficiency, significant associations were found for a number of occlusal and oral factors in the ULR analysis; MOSN and tongue pressure remained significant in the final MLR model. Masticatory efficiency refers to the ability to achieve an adequate degree of comminution of food and is dependent on two major factors: the crushing of the food bolus on the occlusal table and food bolus formation via tongue movement. Therefore, it was not unexpected that both the MOSN and tongue pressure were significant predictors of masticatory efficiency.

With regard to masticatory score, occlusal force and OSN were found to be significant predictors in the ULR analysis; BMI, OSN, and cheek pressure were determined to be significant factors in the final MLR model. Higher masticatory scores were significantly associated with lower cheek pressures. Measuring tongue and cheek pressures was difficult in older participants, and the best performance was not always obtained for these measurements. As a higher cheek pressure is generally preferable for mastication, the reasons for this result remain unclear, despite taking into account the inherent errors in the measurements. In contrast to masticatory efficiency, the influence of oral factors on masticatory score was lower.

No oral factors were found to be significantly associated with VAS satisfaction score in the ULR analysis. Both BMI and age were determined to be significant predictors in the final MLR model. Thus, objective oral factors had a smaller influence on subjective, as opposed to objective, assessments of masticatory ability. VAS satisfaction score decreased with age. Furthermore, it is notable that BMI was found to be significantly associated with the two subjective assessments of masticatory ability (masticatory and VAS satisfaction scores), but not the objective masticatory efficiency test and other oral factors. A possible explanation may be that older individuals adopt strategies including choosing foods with a softer texture, consuming liquid foods e.g., soups, cutting their food into smaller 
pieces, and cooking foods to make them easier to eat, according to their individual masticatory ability. An urgent concern in older individuals, especially in those with frailty and geriatric syndromes, is undernutrition, which confers a high risk of mortality. Previous studies have reported that despite undergoing implant treatment and demonstrating improvements in chewing function, patients may not experience changes in dietary intake, BMI, or blood markers [30-32]. It is also reported that oral physiology and anatomy only explain the variations in oral processing behavior to a limited extent [33]. Therefore, it is apparent that both subjective and objective assessments of masticatory performance are required to facilitate the improvements in nutritional status of older individuals.

This study has four major limitations. First, BMI was used as an assessment of nutritional status because BMI is an easy and non-invasive indicator, and is readily available for significant clinical studies $[1,2,4,5,25]$. However, BMI is just one aspect of nutritional status and is influenced by various lifestyle factors such as physical activity, diet, and general health/disease status). More accurate evaluation of nutritional status could include other tests, such as a mini nutritional assessment $\left(\mathrm{MNA}^{\circledR}\right)$, body composition assessment using, for example, bioelectrical impedance analysis, indicators of gut function, and blood chemistry [34-36]. Additionally, BMI calculations in this study were based on self-reported weight and height, and these were not actually measured. As all participants had a regular physical check-up, the data were considered to be reliable; however, there may have been some bias. Second, assessments of participants' prostheses were not carried out in this study, as the priority was the investigation of oral factors, such as tongue pressure; therefore, the evaluations of masticatory ability may have been affected by the use of existing prostheses. Third, the study lacked statistical power due to the small number of participants. Nevertheless, the number of investigated variables was reduced accordingly, and the same results were obtained in the statistical analyses. Thus, the sample size employed in this study was sufficient to draw conclusions with respect to the primary outcomes. Fourth, the participants in this study were outpatients undergoing regular maintenance at a university hospital; therefore, they were not representative of the general elderly population in Japan.

\section{Conclusions}

In conclusion, objective masticatory efficiency was found to be dependent on oral factors. This is in contrast to subjective assessments of masticatory ability, including masticatory score and VAS satisfaction score, which were dependent on the BMI and not associated with the tested oral factors, with the exception of the MOSN.

The hypothesis could not be fully accepted, and both objective and subjective assessments of masticatory ability, along with considerations of nutritional formulations, will be required for the maintenance and improvement of nutritional status in older individuals.

Author Contributions: Conceptualization, K.F., K.N. and T.I.; methodology, K.F. and K.N.; software, K.F.; validation, K.F. and K.N.; formal analysis, K.F.; investigation, K.F. and H.S.; data curation, K.F.; writing-original draft preparation, K.F. and T.I.; writing — review and editing, T.I.; visualization, K.F.; supervision, K.N. and T.I.; funding acquisition, T.I. All authors have read and agreed to the published version of the manuscript.

Funding: This research received no external funding.

Acknowledgments: The authors would like to thank Seiko Hongama and Tsuyoshi Honda for technical and sampling assistance with the experiments.

Conflicts of Interest: The authors declare no conflict of interest.

\section{References}

1. Flegal, K.M.; Kit, B.K.; Orpana, H.; Graubard, B.I. Association of all-cause mortality with overweight and obesity using standard body mass index categories: A systematic review and meta-analysis. JAMA 2013, 309, 71-82. [CrossRef] [PubMed]

2. Attuquayefio, T.; Stevenson, R.J. A systematic review of longer-term dietary interventions on human cognitive function: Emerging patterns and future directions. Appetite 2015, 95, 554-570. [CrossRef] [PubMed] 
3. CDC. What Causes Overweight and Obesity? Available online: http://www.cdc.gov/obesity/adult/causes/ index.html (accessed on 5 March 2015).

4. Tamakoshi, M.; Kawado, K.; Ozasa, K.; Tamakoshi, Y.; Lin, K.; Yagyu, S.; Kikuchi, S.; Hashimoto, S.; JACC Study Group. Impact of smoking and other lifestyle factors on life expectancy among Japanese: Findings from the Japan Collaborative Cohort (JACC) Study. J. Epidemiol. 2010, 20, 370-376. [CrossRef]

5. Kawakami, Y.; Hamano, J. Changes in Body Mass Index, Energy Intake, and Fluid Intake over 60 Months Premortem as Prognostic Factors in Frail Elderly: A Post-Death Longitudinal Study. Int. J. Environ. Res. Public Health 2020, 17, 1823. [CrossRef] [PubMed]

6. Altenhoevel, A.; Norman, K.; Smoliner, C.; Peroz, I. The impact of self-perceived masticatory function on nutrition and gastrointestinal complaints in the elderly. J. Nutr. Health Aging 2012, 16, 175-178. [CrossRef]

7. Weijenberg, R.A.; Lobbezoo, F.; Knol, D.L.; Tomassen, J.; Scherder, E.J. Increased masticatory activity and quality of life in elderly persons with dementia-a longitudinal matched cluster randomized single-blind multicenter intervention study. BMC Neurol. 2013, 13, 26. [CrossRef]

8. Watson, S.;McGowan, L.; McCrum, L.; Cardwell, C.R.; McGuinness, B.; Moore, C.; Woodside, J.V.; McKenna, G. The impact of dental status on perceived ability to eat certain foods and nutrient intakes in older adults: Cross-sectional analysis of the UK National Diet and Nutrition Survey 2008-2014. Int. J. Behav. Nutr. Phys. Act. 2019, 16, 43. [CrossRef]

9. Shiga, H.; Ishikawa, A.; Nakajima, K.; Tanaka, A. Relationship between masticatory performance using a gummy jelly and food intake ability in Japanese complete denture wearers. Odontology 2015, 103, 356-359. [CrossRef]

10. Takagi, D.; Watanabe, Y.; Edahiro, A.; Ohara, Y.; Murakami, M.; Murakami, K.; Hironaka, S.; Taniguchi, Y.; Kitamura, A.; Shinkai, S.; et al. Factors affecting masticatory function of community-dwelling older people: Investigation of the differences in the relevant factors for subjective and objective assessment. Gerodontology 2017, 34, 357-364. [CrossRef]

11. Van Der Bilt, A.; Olthoff, L.W.; Bosman, F.; Oosterhaven, S.P. Chewing performance before and after rehabilitation of post-canine teeth in man. J. Dent. Res. 1994, 73, 1677-1683. [CrossRef]

12. Osterberg, T.; Carlsson, G.E. Dental state, prosthodontic treatment and chewing ability-A study of five cohorts of 70-year-old subjects. J. Oral Rehabil. 2007, 34, 553-559. [CrossRef] [PubMed]

13. Ikebe, K.; Matsuda, K.; Kagawa, R.; Enoki, K.; Yoshida, M.; Maeda, Y.; Nokubi, T. Association of masticatory performance with age, gender, number of teeth, occlusal force and salivary flow in Japanese older adults: Is ageing a risk factor for masticatory dysfunction? Arch. Oral Biol. 2011, 56, 991-996. [CrossRef] [PubMed]

14. Singh, K.A.; Brennan, D.D. Chewing disability in older adults attributable to tooth loss and other oral conditions. Gerodontology 2012, 29, 106-110. [CrossRef] [PubMed]

15. Kosaka, T.; Ono, T.; Kida, M.; Kikui, M.; Yamamoto, M.; Yasui, S.; Nokubi, T.; Maeda, Y.; Kokubo, Y.; Watanabe, M.; et al. A multifactorial model of masticatory performance: The Suita study. J. Oral Rehabil. 2016, 43, 340-347. [CrossRef]

16. Kikutani, T.; Tamura, F.; Nishiwaki, K.; Kodama, M.; Suda, M.; Fukui, T.; Takahashi, N.; Yoshida, M.; Akagawa, Y.; Kimura, M. Oral motor function and masticatory performance in the community-dwelling elderly. Odontology 2009, 97, 38-42. [CrossRef]

17. Hirai, T.; Ishijima, T.; Koshino, H.; Anzai, T. Age-related change of masticatory function in complete denture wearers: Evaluation by a sieving method with peanuts and a food intake questionnaire method. Int. J. Prosthodont. 1994, 7, 454-460.

18. Koshino, H.; Hirai, T.; Toyoshita, Y.; Yokoyama, Y.; Tanaka, M.; Iwasaki, K.; Hosoi, T. Development of new food intake questionnaire method for evaluating the ability of mastication in complete denture wearers. Prosthodont. Res. Pract. 2008, 7, 12-18. [CrossRef]

19. Shiga, H.; Kobayashi, Y.; Arakawa, I.; Yokoyama, M.; Unno, M. Validation of a portable blood glucose testing device in measuring masticatory performance. Prosthodont. Res. Pract. 2006, 5, 15-20. [CrossRef]

20. Tsuga, K.; Maruyama, M.; Yoshikawa, M.; Yoshida, M.; Akagawa, Y. Manometric evaluation of oral function with a hand-held balloon probe. J. Oral Rehabil. 2011, 38, 680-685. [CrossRef]

21. Matsui, Y.; Ohno, K.; Michi, K.; Suzuki, Y.; Yamagata, K. A computerized method for evaluating balance of occlusal load. J. Oral Rehabil. 1996, 23, 530-535. [CrossRef]

22. Cruz-Jentoft, A.J.; Kiesswetter, E.; Drey, M.; Sieber, C.C. Nutrition, frailty, and sarcopenia. Aging Clin. Exp. Res. 2017, 29, 43-48. [CrossRef] [PubMed] 
23. Lorenzo-Lopez, L.; Maseda, A.; de Labra, C.; Regueiro-Folgueira, L.; Rodriguez-Villamil, J.L.; Millan-Calenti, J.C. Nutritional determinants of frailty in older adults: A systematic review. BMC Geriatr. 2017, 17, 108. [CrossRef]

24. Watanabe, D.; Yoshida, T.; Yokoyama, K.; Yoshinaka, Y.; Watanabe, Y.; Kikutani, T.; Yoshida, M.; Yamada, Y.; Kimura, M.; Kyoto-Kameoka Study Group. Association between Mixing Ability of Masticatory Functions Measured Using Color-Changing Chewing Gum and Frailty among Japanese Older Adults: The Kyoto-Kameoka Study. Int. J. Environ. Res. Public Health 2020, 17, 4555. [CrossRef] [PubMed]

25. Sasaki, S.; Katagiri, A.; Tsuji, T.; Amano, K. Self-reported rate of eating correlates with body mass index in 18-y-old Japanese women. Int. J. Obes. 2003, 27, 1405-1410. [CrossRef] [PubMed]

26. Host, A.; McMahon, A.-T.; Walton, K.; Charlton, K. “While we can, we will”: Exploring food choice and dietary behaviour amongst independent older Australians. Nutr. Diet. 2016, 73, 463-473. [CrossRef]

27. Whitelock, E.; Ensaff, H. On Your Own: Older Adults' Food Choice and Dietary Habits. Nutrients 2018, 10, 413. [CrossRef] [PubMed]

28. Vettori, V.; Lorini, C.; Milani, C.; Bonaccorsi, G. Towards the Implementation of a Conceptual Framework of Food and Nutrition Literacy: Providing Healthy Eating for the Population. Int. J. Environ. Res. Public Health 2019, 16, 5041. [CrossRef]

29. Hildebrandt, G.H.; Dominguez, B.L.; Schork, M.A.; Loesche, W.J. Functional units, chewing, swallowing, and food avoidance among the elderly. J. Prosthet. Dent. 1997, 77, 588-595. [CrossRef]

30. Awad, M.A.; Morais, J.A.; Wollin, S.; Khalil, A.; Gray-Donald, K.; Feine, J.S. Implant overdentures and nutrition: A randomized controlled trial. J. Dent. Res. 2012, 91, 39-46. [CrossRef]

31. Boven, G.C.; Raghoebar, G.M.; Vissink, A.; Meijer, H.J.A. Improving masticatory performance, bite force, nutritional state and patient's satisfaction with implant overdentures: A systematic review of the literature. J. Oral Rehabil. 2015, 42, 220-233. [CrossRef]

32. Müller, F.; Duvernay, E.; Loup, A.; Vazquez, L.; Herrmann, F.R.; Schimmel, M. Implant-supported mandibular overdentures in very old adults: A randomized controlled trial. J. Dent. Res. 2013, 92, 154-160. [CrossRef] [PubMed]

33. Ketel, E.C.; de Wijk, R.A.; de Graaf, C.; Stieger, M. Relating oral physiology and anatomy of consumers varying in age, gender and ethnicity to food oral processing behavior. Physiol. Behav. 2020, 215, 112766. [CrossRef] [PubMed]

34. Vellas, B.; Guigoz, Y.; Garry, P.J.; Nourhashemi, F.; Bennahum, D.; Lauque, S.; Albarede, J.L. The Mini Nutritional Assessment (MNA) and its use in grading the nutritional state of elderly patients. Nutrition 1999, 15, 116-122. [CrossRef]

35. Solemdal, K.; Sandvik, L.; Møinichen-Berstad, C.; Skog, K.; Willumsen, T.; Mowe, M. Association between oral health and body cell mass in hospitalised elderly. Gerodontology 2012, 29, e1038-e1044. [CrossRef] [PubMed]

36. Zhang, Z.; Pereira, S.L.; Luom, M.; Matheson, E.M. Evaluation of Blood Biomarkers Associated with Risk of Malnutrition in Older Adults: A Systematic Review and Meta-Analysis. Nutrients 2017, 9, 829. [CrossRef] [PubMed]

(C) 2020 by the authors. Licensee MDPI, Basel, Switzerland. This article is an open access article distributed under the terms and conditions of the Creative Commons Attribution (CC BY) license (http://creativecommons.org/licenses/by/4.0/). 